\title{
Brachial Plexus Injuries in Adults with Traumatic Brain Injury : A Retrospective Study
}

\author{
Nihal Tezel, ${ }^{1}$ Aslı Can, ${ }^{1}$ Damla Cankurtaran, ${ }^{1}$ Ece Ünlü Akyüz, ${ }^{1}$ Aytül Çakcı ${ }^{2}$ \\ Department of Physical Medicine and Rehabilitation,' University of Health Sciences Diskapi Yildirim Beyazit Training and Research Hospital, \\ Ankara, Turkey \\ Department of Physical Medicine and Rehabilitation, ${ }^{2}$ Losante Hospital, Ankara, Turkey
}

Objective : We aimed to investigate the presence of brachial plexus injury (BPI) in traumatic brain injury (TBI) patients and to draw attention to BPI, which can be overlooked by physicians in TBI patients.

Methods : The study was designed retrospectively by examining the files of 58 patients with moderate to severe TBI to investigate coexistence of TBI and BPI.

Results : BPI was detected in six of 58 TBI patients (10.3\%). BPI was detected after an average 116 days from the initial injury. Three patients had lower trunk BPI and three patients had panplexopathy.

Conclusion : Diagnosis of BPI in patients with TBI is delayed in the acute period of injury. The clinicians should keep in mind that BPIs may occur and remain undiagnosed in patients with TBI.

Key Words : Brachial plexus - Brain injuries, Traumatic · Electromyography.

\section{INTRODUCTION}

Traumatic brain injury (TBI) is a brain dysfunction caused by an external source ${ }^{8)}$. Trauma to the brain can lead to a wide variety of long-term pathological changes. Although TBI affects all ages, it is mostly seen in children, adolescents, and over 75 years of age ${ }^{12)}$.

Both the central nervous system (CNS) and the peripheral nervous system may be deteriorated as a result of $\mathrm{TBI}^{3)}$. As muscle weakness and sensory deficits are often attributed to the CNS injuries, peripheral nerve injuries (PNIs) may be missed in patients with $\mathrm{TBI}^{13)}$. Life-threatening injuries need to be treated in the acute phase and a detailed orthopedic examination may be lacking sometimes. These factors may delay the diagnosis of concomitant PNIs such as brachial plexus injuries (BPIs) in patients with TBI.

BPIs are PNIs that may lead to motor and sensory deficits, pain, functional limitation, and impaired quality of life ${ }^{4}$. They are most commonly caused by direct trauma, especially motor vehicle accidents. It has been known that BPIs also may accompany $\mathrm{TBI}^{4)}$. However, in the literature, there are only a few studies to evaluate BPI in patients with $\mathrm{TBI}^{14)}$. The aims of

- Received : June 27, 2020 •Revised : July 27, 2020 •Accepted : August 29, 2020

- Address for reprints : Nihal Tezel

Department of Physical Medicine and Rehabilitation, University of Health Sciences Diskapi Yildirim Beyazit Training and Research Hospital, Şehit Ömer Halisdemir Street, No:1, Altindag, Ankara 06110, Turkey

Tel : +90 031259620 00, Fax : +90 031231866 90, E-mail : nihaltezel@gmail.com, ORCID : https://orcid.org/0000-0002-7623-7827

This is an Open Access article distributed under the terms of the Creative Commons Attribution Non-Commercial License (http://creativecommons.org/licenses/by-nc/4.0) which permits unrestricted non-commercial use, distribution, and reproduction in any medium, provided the original work is properly cited. 
the study were to investigate the presence of BPI in TBI patients and to draw attention to BPI, which can be overlooked by physicians in TBI patients.

\section{MATERIALS AND METHODS}

The study protocol was approved by the local Ethics Committee (approve date : March 2, 2020, approve number : 83/08). The study was conducted in accordance with the principles of the Declaration of Helsinki. The study was designed retrospectively by examining the files of 58 patients with moderate to severe TBI. All patients received inpatient treatment in a physical medicine and rehabilitation clinic between

Table 1. Demographic features and disease characteristics of the TBI patients

\begin{tabular}{lc}
\hline Characteristic & TBI patients $(\mathbf{n = 5 8 )}$ \\
\hline Age (years) & $32.84 \pm 14.07$ \\
Gender & $14(24.1)$ \\
Female & $44(75.9)$ \\
Male & \\
Educational status & $0(0.0)$ \\
Illiterate & $0(0.0)$ \\
Literate & $25(43.1)$ \\
Primary school & $18(31.0)$ \\
Secondary school & $10(17.3)$ \\
High school & $5(8.6)$ \\
University or higher & $33(56.9)$ \\
Tracheostomy & $35(60.3)$ \\
Gastrostomy & $0(0.0)$ \\
Mechanical ventilation & $44(75.9)$ \\
Speech disorder & $45(77.6)$ \\
Bladder dysfunction & $44(75.9)$ \\
Bowel dysfunction & $15.48 \pm 7.87$ \\
DRS (0-29) & $24.81 \pm 16.72$ \\
FIM & $15.60 \pm 10.57$ \\
Motor & $41.20 \pm 25.72$ \\
\hline Cognitive & \\
\hline Total score & \\
\hline
\end{tabular}

Values are presented as mean \pm standard deviation or number (\%). TBI traumatic brain injury, DRS : disability rating scale, FIM : functional independent measurement
Table 2. Demographic features and disease characteristics of the TBI patients with brachial plexopathy

\begin{tabular}{|c|c|}
\hline Characteristic & TBI patients with BPI $(n=6)$ \\
\hline Age (years) & $27.6 \pm 10.2$ \\
\hline \multicolumn{2}{|l|}{ Gender } \\
\hline Female & 1 \\
\hline Male & 5 \\
\hline \multicolumn{2}{|l|}{ Educational status } \\
\hline Illiterate & 0 \\
\hline Literate & 1 \\
\hline Primary school & 1 \\
\hline Secondary school & 2 \\
\hline High school & 2 \\
\hline \multicolumn{2}{|l|}{ University or higher } \\
\hline \multicolumn{2}{|l|}{ Hand dominancy } \\
\hline Right & 6 \\
\hline \multicolumn{2}{|l|}{ Left } \\
\hline Tracheostomy & 2 \\
\hline Gastrostomy & 1 \\
\hline Mechanical ventilation & 0 \\
\hline Speech disorder & 4 \\
\hline Bladder dysfunction & 1 \\
\hline Bowel dysfunction & 1 \\
\hline DRS (0-29) & $13.59 \pm 4.48$ \\
\hline \multicolumn{2}{|l|}{ FIM } \\
\hline Motor & $31 \pm 18$ \\
\hline Cognitive & $29.3 \pm 9.8$ \\
\hline \multicolumn{2}{|l|}{ Total score } \\
\hline \multicolumn{2}{|l|}{ BPI side } \\
\hline Right & 1 \\
\hline Left & 5 \\
\hline BPI detection time after injury (days) & $116 \pm 3$ \\
\hline \multicolumn{2}{|l|}{ Types of BPI } \\
\hline Lower trunk injury & 3 \\
\hline Panplexopathy & 3 \\
\hline \multicolumn{2}{|l|}{ Etiology of Injury } \\
\hline Traffic accident & 4 \\
\hline Work accident & 1 \\
\hline Gunshot injury & 1 \\
\hline \multicolumn{2}{|l|}{ Mechanism of Injury } \\
\hline Traction & 4 \\
\hline Penetration & 1 \\
\hline Avulsion & 1 \\
\hline Proximal humerus fracture & 3 \\
\hline Proximal humerus and clavicula fracture & 1 \\
\hline
\end{tabular}


January 2017 and December 2019.

The patients aged between 18 and 60 and diagnosed with BPI according to electroneuromyographic findings were included in the study. In our rehabilitation clinic, BPI is suspect- ed in patients with upper extremity atrophy, hyporeflexia/areflexia, flaccid muscle tone, do not have expected motor recovery, and shoulder girdle fracture. To confirm the diagnosis, electroneuromyography (ENMG) is performed. Patients

Table 3. MRC* grades of affected muscles of patients with BPI

\begin{tabular}{|c|c|c|c|c|c|c|}
\hline & No. 1 patient & No. 2 patient & No. 3 patient & No. 4 patient & No. 5 patient & No. 6 patient \\
\hline Brachial plexus lesion & Panplexopathy & Panplexopathy & Panplexopathy & $\begin{array}{l}\text { Lower trunk injury } \\
\text { (severe) }\end{array}$ & $\begin{array}{l}\text { Lower trunk injury } \\
\text { (severe) }\end{array}$ & $\begin{array}{c}\text { Lower trunk injury } \\
\text { (severe) }\end{array}$ \\
\hline Time of evaluation (days) & 92 & 104 & 110 & 90 & 134 & 168 \\
\hline Deltoid & 1 & 0 & $5 / 5$ & $5 / 5$ & $4 / 5$ & $3 / 5$ \\
\hline Supraspinatus & 1 & 0 & $3 / 5$ & $5 / 5$ & $3 / 5$ & $3 / 5$ \\
\hline Pectoralis & 1 & 0 & $5 / 5$ & $5 / 5$ & $4 / 5$ & $3 / 5$ \\
\hline Biceps & 0 & 0 & $4 / 5$ & $5 / 5$ & $3 / 5$ & $3 / 5$ \\
\hline Triceps & 0 & 0 & $4 / 5$ & $5 / 5$ & $4 / 5$ & $3 / 5$ \\
\hline ECRL-ECRB & 0 & 0 & $4 / 5$ & $5 / 5$ & $3 / 5$ & $3 / 5$ \\
\hline FDS-FDP & 4 & 0 & $4 / 5$ & $0 / 5$ & $1 / 5$ & $3 / 5$ \\
\hline
\end{tabular}

* 0 : no contraction, 1 : flicker of contraction, 2 : active movement, with gravity eliminated, 3 : active movement against gravity, $4:$ active movement against gravity and resistance, 5 : muscle contracts normally against full resistance. MRC: Medical Research Council, BPI : brachial plexus injury, ECRL : extensor carpi radialis longus, ECRB : extensor carpi radialis brevis, FDS : flexor digitorum superficialis, FDP : flexor digitorum profundus

Table 4. Electrophysiologic findings of the patients

\begin{tabular}{|c|c|c|c|c|}
\hline Patient & Localisation, root/trunk & SNAP & CMAP & Neddle EMG \\
\hline \multirow[t]{3}{*}{ No. 1 patient } & C5-6/upper & $A$ & A & Reduced activity/SA :+ \\
\hline & C7/middle & A & $A$ & Reduced activity/SA : + \\
\hline & C8-T1/lower & $A$ & $A$ & Reduced activity/SA : + \\
\hline \multirow[t]{3}{*}{ No. 2 patient } & C5-6/upper & A & A & No activity/SA : none \\
\hline & c7/middle & A & A & No activity/SA : none \\
\hline & C8-T1/lower & A & A & No activity/SA : + \\
\hline \multirow[t]{3}{*}{ No. 3 patient } & C5-6/upper & A & $\mathrm{D}$ & Reduced activity/SA : none \\
\hline & C7/middle & $A$ & $\mathrm{D}$ & Reduced activity/SA : none \\
\hline & C8-T1/lower & A & $\mathrm{D}$ & Reduced activity/SA : + \\
\hline \multirow[t]{3}{*}{ No. 4 patient } & C5-6/upper & $\mathrm{N}$ & $\mathrm{N}$ & $\mathrm{N}$ \\
\hline & c7/middle & $\mathrm{N}$ & $\mathrm{N}$ & $\mathrm{N}$ \\
\hline & C8-T1/lower & A & $D$ & No activity/SA : + \\
\hline \multirow[t]{3}{*}{ No. 5 patient } & C5-6/upper & $\mathrm{N}$ & N & N \\
\hline & C7/middle & $\mathrm{N}$ & N & N \\
\hline & C8-T1/lower & $A$ & $A$ & No activity/SA : + \\
\hline \multirow[t]{3}{*}{ No. 6 patient } & C5-6/upper & $\mathrm{N}$ & N & N \\
\hline & C7/middle & $\mathrm{N}$ & $\mathrm{N}$ & $\mathrm{N}$ \\
\hline & C8-T1/lower & $A$ & $D$ & Reduced activity/SA : + \\
\hline
\end{tabular}

SNAP : sensory nerve action potential, CMAP : compound motor action potantial, EMG : electromyography, A : absent, SA : spontaneous activity, D : diminished, $\mathrm{N}$ : normal 
with a history of upper extremity PNI were excluded from the study. Demographic, clinical, and electromyographic data of the patients with TBI and BPI were recorded.

\section{Statistics}

Descriptive statistics were performed for demographic and clinical characteristics of the patients. Continuous variables were presented as mean \pm standard deviation. Categorical variables were presented as frequencies. Statistical analysis was performed using the PASW version 17.0 software (SPSS Inc, Chicago, IL, USA).

\section{RESULTS}

Fifty-eight patients with TBI were screened for the presence of BPI. The demographic and clinic characteristics of all patients with TBI were summarized in Table 1.

Brachial plexus injury was detected in six of $58 \mathrm{TBI}$ patients
(10.3\%). Five patients were male and one patient was female. All patients were right-handed. BPI was on the right side in one patient and on the left side in five patients. BPI was detected after an average 116 days from the initial injury. Three patients had lower trunk brachial plexus injury and three patients had panplexopathy.

The etiology of injury was a traffic accidents in four patients, work-related accident in one patient, and gunshot injury in one patient. The mechanism of injury was traction in four patients, avulsion in one patient, and laceration in one patient. Four patients had proximal humerus fracture and one patient had proximal humerus and clavicle fractures in affected upper extremity. The demographic and clinic characteristics of TBI patients with BPI were summarized in Table 2. ENMG findings and Medial Research Council grades of affected muscles of patients with BPI has been shown in Tables 3 and 4 .

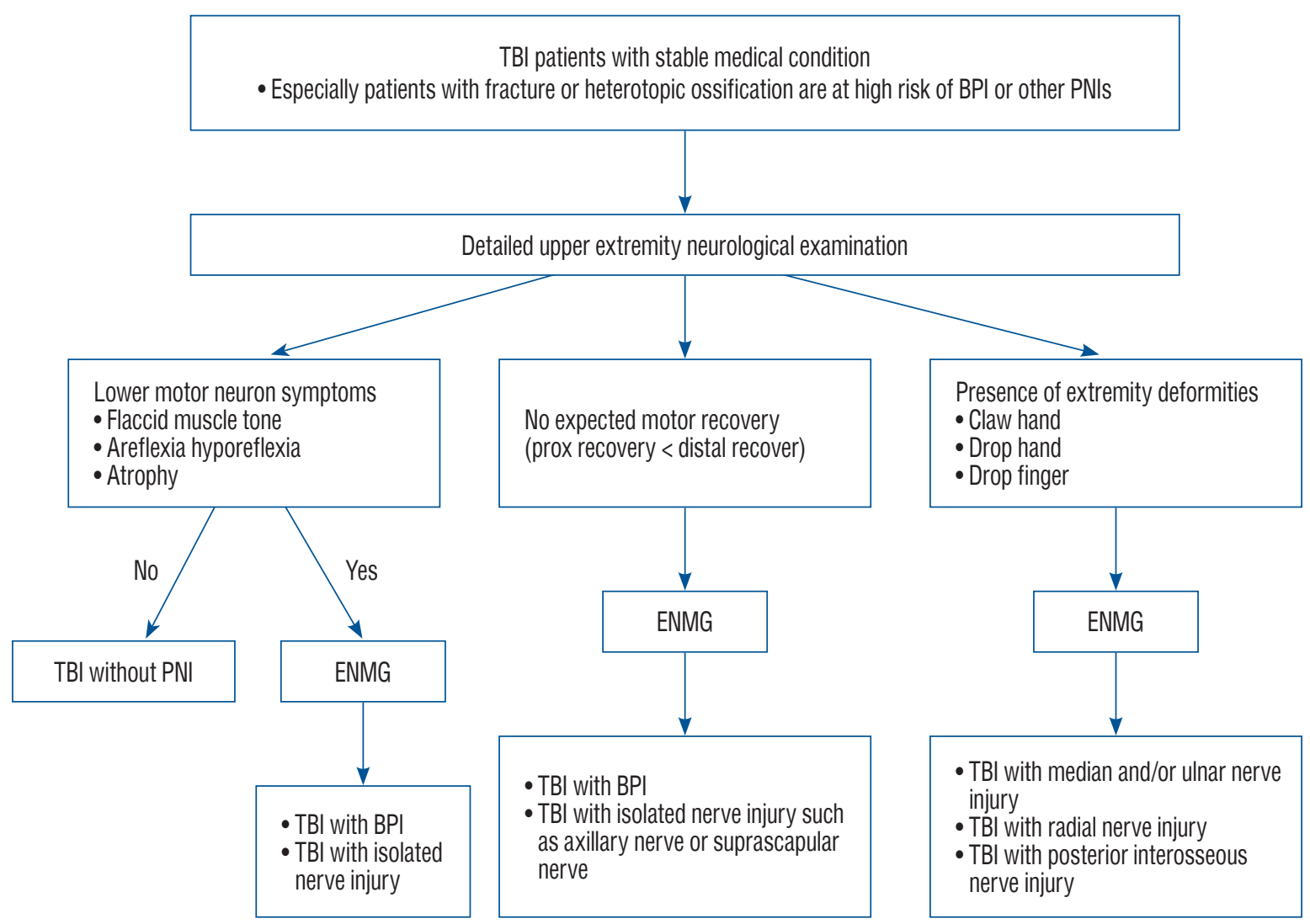

Fig. 1. The flow-sheet for diagnosis fo BPI and other PNIs of upper extremity in TBI patients. TBI : traumatic brain injury, BPI : brachial plexus injury, PNIs : peripheral nerve injuries, ENMG : electroneuromyography. 


\section{DISCUSSION}

TBI is a serious, well recognized public health problem around the worldwide. It is an important cause of mortality and morbidity ${ }^{7}$. Aside from associated CNS trauma, there may be injuries to peripheral nerves. Concomitant PNIs such as BPIs contribute to functional disability and can lead to unemployment and economic burden in patients with TBI.

In a previous study, Stone and Keenan ${ }^{14)}$ detected PNI in $34 \%$ of 50 TBI patients. Ten percent of these patients had BPI. They also reported that none of the BPI patients was detected at the time of $\mathrm{TBI}^{14)}$. Ciaramitaro et al. ${ }^{2)}$ investigated the epidemiological data of traumatic nerve injuries. They found that the concomitance of traumatic nerve lesion and TBI was approximately $15 \%$. They also reported that the diagnosis may delay due to changes in consciousness ${ }^{2)}$. Similarly, in the present study, 10\% of patients with TBI had a concomitant BPI. The diagnosis of BPI was made after average of 116 days from the head trauma. According to these results, it is possible to obtain an idea that BPI is commonly accompanied to TBI, and recognition of BPI is often overlooked at the time of initial injury.

Traumatic BPIs are most commonly secondary to high-energy trauma, especially motor vehicle accidents and, less commonly, secondary to falls, bullet injuries, and penetrating injuries with a sharp object. Suggested mechanisms of the injury are traction, avulsion, laceration, compression, and contu$\operatorname{sion}^{6,11)}$. In this study, the major etiology was motor vehicle accidents. The other causes were bullet injury and work-related accidents. The most common injury mechanism was traction and the others were avulsion and laceration. Similar to our results, Stone and Keenan ${ }^{14)}$ observed that major etiology and mechanism were traction-induced motor vehicle accidents in patients with TBI and concomitant BPI.

The association between proximal humerus or clavicle fractures and BPI has been previously reported ${ }^{5,11}$. Fractures of proximal humerus or clavicle may lead to the traction of brachial plexus. In addition, brachial plexus may be compressed by fractures of these bones ${ }^{11)}$. In the present study, three BPI patients had proximal humerus fracture, and one patient had proximal humerus and clavicula fractures together. In contrast to our results, Stone and Keenan ${ }^{14)}$ did not observe any upper extremity fracture in their TBI patients with concomitant BPI.
It seems that the prevalence of BPI in TBI patients is higher than previously suspected. It is often overlooked by clinicians because motor deficits are often attributed to the CNS injury. In addition, unstable medical condition, impaired cognitive functioning, or inadequately treated proximal humerus and/ or clavicle fractures may lead to unrecognized BPI. Even though the patients do not report any complaints, the clinician should keep in mind that BPI can be seen concomitant in TBI patients, especially those with the proximal humerus or clavicle fractures ${ }^{1,9,10)}$. Detailed neurological examination is crucial for the diagnosis of BPI and should be performed periodically after stabilization of medical condition. Patients with TBI typically present with upper motor neuron symptoms of spasticity, weakness, clonus, pathologic reflexes, and hyperreflexia in the affected extremities. In the presence of BPI, lower motor neuron symptoms such as flaccid muscle tone, areflexia/hyporeflexia, and muscle atrophy are detected. In addition, patients who do not have expected motor recovery in the affected extremity should be assessed for BPI. ENMG should be performed in TBI patients with clinical suspicion of BPI. ENMG is the most important diagnostic tool for assessing BPI. It gives not only information about the diagnosis, but also about the localization, severity, and prognosis of BPI. The flow-sheet for diagnosis of BPI and other PNIs of the upper extremity in TBI patients has been shown in Fig. 1.

There were some limitations in our study. First, the number of patients analyzed was limited. Second, this study was a single-center study. Future studies with a larger sample size are needed to confirm the results of this study.

\section{CONCLUSION}

The diagnosis of BPI in patients with TBI is delayed in the acute period of injury because of unstable medical condition, impaired cognitive functioning or inadequately treated shoulder girdle fractures. The clinicians should keep in mind that BPIs may occur and remain undiagnosed in patients with TBI. Detailed neurological examination should be performed in all TBI patients after stabilization of medical condition and in patients with clinical suspicion of BPI, ENMG should be considered. 


\section{CONFLICTS OF INTEREST}

No potential conflict of interest relevant to this article was reported.

\section{INFORMED CONSENT}

This type of study does not require informed consent.

\section{AUTHOR CONTRIBUTIONS}

\author{
Conceptualization : NT, AC \\ Data curation : NT, AC, AÇ \\ Formal analysis : DC \\ Methodology : EÜA \\ Project administration : NT, AC \\ Visualization : NT, AC \\ Writing - original draft : NT, AC \\ Writing - review \& editing : EÜA, AÇ
}

\section{ORCID}

$\begin{array}{lr}\text { Nihal Tezel } & \text { https://orcid.org/0000-0002-7623-7827 } \\ \text { Aslı Can } & \text { https://orcid.org/0000-0002-4189-7323 } \\ \text { Damla Cankurtaran } & \text { https://orcid.org/0000-0002-6208-3345 } \\ \begin{array}{ll}\text { Ece Ünlü Akyüz } & \text { https://orcid.org/0000-0003-4718-5981 } \\ \text { Aytül Çakc1 } & \text { https://orcid.org/0000-0002-2121-9330 }\end{array}\end{array}$

\section{References}

1. Brien WW, Gellman H, Becker V, Garland DE, Waters RL, Wiss DA :
Management of fractures of the humerus in patients who have an injury of the ipsilateral brachial plexus. J Bone Joint Surg Am 72 : 12081210, 1990

2. Ciaramitaro P, Mondelli M, Logullo F, Grimaldi S, Battiston B, Sard A, et al. : Traumatic peripheral nerve injuries: epidemiological findings, neuropathic pain and quality of life in 158 patients. J Peripher Nerv Syst 15 : 120-127, 2010

3. Dang $B$, Chen $W$, He W, Chen $G$ : Rehabilitation treatment and progress of traumatic brain injury dysfunction. Neural Plast 2017 : 1582182, 2017

4. de Moraes FB, Kwae MY, da Silva RP, Porto CC, Magalhães Dde P, Paulino MV : Clinical aspects of patients with traumatic lesions of the brachial plexus following surgical treatment. Rev Bras Ortop 50 : 556561, 2015

5. Garland DE, Keenan MA : Orthopedic strategies in the management of the adult head-injured patient. Phys Ther $63:$ 2004-2009, 1983

6. Kim DH, Murovic JA, Kline DG : Brachial plexus injury: mechanisms, surgical treatment and outcomes. Korean Neurosurg Soc 36 : 177-185, 2004

7. Mansukhani KA : Electrodiagnosis in traumatic brachial plexus injury. Ann Indian Acad Neurol 16 : 19-25, 2013

8. Menon DK, Schwab K, Wright DW, Maas Al; Demographics and Clinical Assessment Working Group of the International and Interagency Initiative toward Common Data Elements for Research on Traumatic Brain Injury and Psychological Health : Position statement: definition of traumatic brain injury. Arch Phys Med Rehabil 91 : 1637-1640, 2010

9. Midha R : Epidemiology of brachial plexus injuries in a multitrauma population. Neurosurgery 40 : 1182-1189, 1997

10. Noble J, Munro CA, Prasad VS, Midha R : Analysis of upper and lower extremity peripheral nerve injuries in a population of patients with multiple injuries. J Trauma 45 : 116-122, 1998

11. Park HR, Lee GS, Kim IS, Chang JC : Brachial plexus injury in adults. The Nerve 3 : 1-11, 2017

12. Robbins W, Cifu D : Geriatric Traumatic Brain Injury in Eapen BC, Cifu DX (eds) : Rehabilitation After Traumatic Brain Injury, ed 1. St. Louis : Elsevier, 2018, pp109-114

13. Robinson LR : Traumatic injury to peripheral nerves. Muscle Nerve 23 : 863-873, 2000

14. Stone $L$, Keenan MA : Peripheral nerve injuries in the adult with traumatic brain injury. Clin Orthop Relat Res (233) : 136-144, 1988 